\title{
BASES PARA UM REFERENCIAL TEÓRICO SOBRE O FENÔMENO DA COGNIÇÃO
}

Adelson Fernandes Moreira ${ }^{1}$

Oto Borges ${ }^{2}$

\section{RESUMO}

Apresentamos um referencial teórico para investigar a sala de aula, que articulamos a partir das seguintes matrizes teórico-metodológicas: cognição situada, etnometodologia, fundamentos biológicos da cognição, cognição distribuída e fenomenologia. Discutimos as contribuições que extraímos dessas matrizes ao longo de uma investigação que comparou as práticas de interpretação de alunos em diferentes ambientes de aprendizagem. Com base nessa discussão propomos direções para olhar a sala de aula, que se articulam em torno da afirmação da cognição como fenômeno. A cognição, como processo de produção de conhecimento, é materialmente e socialmente distribuída. Portanto, é situada e, como fenômeno, expressa a ação de uma consciência que se projeta para fora do indivíduo, constituindo os objetos do mundo.

Palavras-chave: ambientes de aprendizagem, cognição situada, fenomenologia.

\section{ABSTRACT}

This paper is aimed at presenting a theoretical framework for investigating the classroom. It was articulated from the following theoretical and methodological frameworks: situated cognition, ethno-methodology, biological foundations of cognition, distributed cognition and phenomenology. The contributions from these frameworks were grasped in the course of an inquiry in which we seek to compare some features of the interpretative practices of students in different learning environments. The results of the theoretical study, in a continuous dialogue with the investigation practice, were articulated to provide directions to look at the classroom. Cognition, as a knowledge production process, is understood as socially and materially distributed. Then, it is situated, and as a phenomenon, expresses consciousness's action of projecting itself out of the being, constituting the world's objects.

Keywords: learnign environments, situated cognition, phenomenology.

\footnotetext{
${ }^{1}$ Coordenação de Ciências-CEFET-- Adelson@ deii.cefetmg.br

${ }^{2}$ Apoio: CNPQ ;Universidade Federal de Minas Gerais- Oto@coltec.ufmg.br
} 


\section{1 - Introdução}

Neste trabalho propomos um referencial de investigação dos processos em sala de aula, dentro de uma abordagem ecológica. Esse referencial foi utilizado em uma pesquisa sobre as práticas de interpretação dos alunos dentro de uma seqüência de ensino desenvolvida em diferentes ambientes de aprendizagem, cada um deles estruturado em torno de uma mediação principal: experimentos com objetos concretos, livro didático e animações no computador (MOREIRA, 2003). A construção do referencial foi se fazendo na medida em que esses ambientes foram sendo investigados, a partir de registros em áudio e vídeo. O que norteou o processo foi o desejo de captar o movimento real da sala de aula e suas interações, no momento em que ocorrem, e a busca de produzir resultados de investigação os quais possam ser reconhecidos pelo professor como advindos de uma experiência concreta.

Buscamos nos estudos sobre o caráter situado e distribuído da cognição, os fundamentos biológicos da cognição, a fenomenologia e a etnomedologia as bases teóricas e metodológicas para o tipo de pesquisa que intentávamos conduzir, comparando as práticas de interpretação dos alunos nos diferentes ambientes de aprendizagem. Esse conjunto de referências ganhou uma primeira organização na medida em que a investigação foi também apresentando seus primeiros resultados. Portanto, não se trata de referências estruturadas, a priori, que conduziram certo trabalho de pesquisa. São referências constituídas e articuladas no caminhar da investigação, através do diálogo permanente entre observação, descrição, pressupostos teóricos, formas de apresentar e discutir os dados com os pares e hipóteses de descrição de situações da sala de aula.

Esse artigo expressa um esforço de síntese. Ao apresentá-la, objetivamos colocar em discussão as construções teóricas de nosso percurso e, também, contribuir para a proposição de referências que fundamentem pesquisas, que se aproximem da sala de aula, no seu fazer, no seu realizar.

Discutimos o caráter situado da cognição. A partir dessa discussão, argumentamos a favor da importância de se retirar a percepção da periferia do estudo dos processos cognitivos. Propomos uma articulação entre uma abordagem situada da cognição e a perspectiva etnometodológica. Tal perspectiva fundamenta uma abordagem eminentemente descritiva da sala de aula e a possibilidade de fazê- 
la a partir de narrativas, construídas com base nos registros em áudio e vídeo do que acontece na sala de aula.

Em seguida, trazemos contribuições do estudo sobre os fundamentos biológicos da cognição e de seu caráter distribuído. Com base no conceito de acoplamento estrutural, propomos o estudo da sala de aula com base na unidade de análise aprendiz-agindo-no-ambiente-de-aprendizagem.

A discussão relativa aos fundamentos biológicos da cognição e a pergunta sobre como conhecemos abre as portas para as contribuições da fenomenologia, especialmente a partir da discussão sobre intencionalidade e a ação constitutiva da consciência.

Essa seqüência de apresentação das referências vai tecendo uma estrutura. O que é apresentado antes prepara e dá significado ao que vem em seguida, chegando ao final a um conjunto de direções para olhar a sala de aula. De início, resumimos essa articulação afirmando a cognição como fenômeno. Embora tenha uma dimensão individual, a cognição, como processo, abarca o indivíduo, mas está para além dele, congregando e integrando diferentes fontes materiais e humanas com o indivíduo. A cognição, como processo de produção de conhecimento, é materialmente e socialmente distribuída. Portanto, é situada e, como fenômeno, expressa a ação de uma consciência que se projeta para fora do indivíduo, constituindo os objetos do mundo.

\section{2 - A natureza situada da cognição}

Nosso estudo sobre cognição situada fez-se a partir dos trabalhos de William Clancey relacionados à construção de sistemas inteligentes cada vez mais flexíveis. Suas contribuições para a teoria da cognição situada ocorrem em um movimento de crítica aos modelos simbólicos e na busca de entender a cognição humana para além da metáfora da mente como um computador.

CLANCEY (1997) apresenta a cognição situada como uma abordagem sobre a natureza do conhecimento, que enfatiza o papel da realimentação e da organização mútua entre as diferentes fontes de cognição - incluindo o sujeito com suas ações e processos mentais subjacentes - e da emergência de uma elaboração sempre nova no comportamento inteligente. 
A teoria da cognição situada, apresentada por Clancey, tem como base a visão de que pensamento e ação humanos são adaptados ao ambiente. Vem daí o significado do adjetivo 'situada'. O que as pessoas percebem, como elas concebem sua atividade, o que fazem são processos que se desenvolvem coordenada e simultaneamente. Toda ação humana é parcialmente improvisada na medida em que se faz por um mecanismo de acoplamento que integra percepção, concepção e ação.

Clancey destaca os avanços conseguidos nos trabalhos de inteligência artificial, fundados na visão de que o conhecimento consiste de modelos descritivos, isto é, representações de como são as coisas e de como agir em determinadas situações. Tal abordagem é por ele nomeada como modelo cognitivo simbólico e possibilitou um grande progresso no entendimento do conhecimento de um especialista. $\mathrm{O}$ que seria modelar o conhecimento de um especialista a partir dessa perspectiva? Dada uma situação problemática, descrevê-la com minúcia de detalhes e, sobre essa base de dados, aplicar um conjunto de procedimentos advindos de teorias aplicáveis em uma situação específica.

Mas, certamente, na atuação de um especialista há algo mais. Há uma flexibilidade que não pode ser reproduzida por programas de computador. Os estudos de cognição situada, segundo Clancey, buscam compreender os fundamentos dessa flexibilidade. Na perspectiva da cognição situada, modelar o conhecimento humano em um conjunto de descrições, tais como uma coleção de fatos e regras em um sistema especialista, é descrever como um programa de computador deveria se comportar em situações particulares. Tal modelo não captura toda a flexibilidade decorrente de como percepção, ação e memória estão relacionadas. Modelo simbólico, representação de conhecimento é diferente de conhecimento. A descrição ou representação do que faz um especialista não abrange todos os processos que ele articula no transcurso de uma ação.

Clancey ancora suas contribuições na psicologia funcionalista de BARTLETT (1932/1977), e na filosofia pragmatista de JAMES (1974) e DEWEY (1974a, 1974b). Para esses estudiosos, o mecanismo de memória, que coordena percepção e ação, é bastante diferente de descrições armazenadas, fundamento dos modelos descritivos simbólicos. De Bartlett, Clancey tira implicações para uma teoria da cognição que concebe o organismo como um todo, dentro de sua experiência cotidiana de perceber e agir dentro de um contexto. 
Clancey reconhece as descrições como fundamentais para a ação humana, mas entende que seu papel não é controlar diretamente o que fazemos, no sentido estrito de uma instrução a guiar o comportamento. São as descrições que nos permitem refletir sobre e, portanto, ir além do comportamento meramente reativo. Quando falamos e escrevemos, estendemos nossa atividade cognitiva para o ambiente a nossa volta, sustentamos concepções, interferimos no ambiente através delas e organizamos concepções alternativas, em um processamento mental permanente.

Clancey propõe a seguinte questão: se o conhecimento humano não consiste em descrições armazenadas, qual é então a relação entre o que dizemos e o que fazemos? Para o autor, falar não deve ser entendido como trazer para fora o que já está dentro, mas como uma forma de mudar o que está dentro. Falar é em si uma atividade de representação e não uma mera enunciação de algo armazenado dentro da mente. Nossos nomes para as coisas e os seus significados, nossas teorias e nossas concepções desenvolvem-se e se modificam de forma concomitante à nossa ação, na medida em que interagimos e percebemos o que nós e os outros fizemos e dissemos previamente. Do ponto de vista da cognição situada, olhar, perceber, entender, descrever são ações que se realimentam mútua e continuamente. Clancey nomeia tal visão como perspectiva transacional.

Para Clancey, cognição situada é o estudo de como o conhecimento humano se desenvolve enquanto um meio de coordenação da atividade, no momento em que ela ocorre. Isto significa que a realimentação proporcionada pelo ambiente material e social e por mecanismos internos ao sujeito, durante o transcurso da ação, desempenha um papel fundamental. O conhecimento tem, portanto, um aspecto dinâmico tanto em sua formação quanto em seu conteúdo. O autor salienta uma mudança de perspectiva de conhecimento como um artefato armazenado para conhecimento enquanto capacidade construída na ação (CLANCEY, 1997:4). Ao destacar a importância da realimentação na produção do conhecimento, Clancey explica que ela pode ocorrer em três formas:

- ações de curto termo mudam o fluxo de dados sensoriais: o que fazemos modifica o ambiente a nossa volta, portanto, condiciona a percepção e produz novas fontes de dados e informações;

- percepção e concepção estão dinamicamente acopladas: nossa compreensão do contexto no qual agimos determina o que percebemos e 
o significado que atribuímos ao percebido. Reciprocamente, o que percebemos constitui a base a partir da qual fazemos abstrações, elaboramos e compreendemos conceitos;

- objetivos e significado são reconcebidos como transformações produzidas no ambiente de acordo com a percepção que temos dele: o papel a que nos atribuímos em certo contexto condiciona nossas percepções e as possíveis ações que desejamos fazer ou julgamos pertinentes.

Clancey compreende o termo situado como possuindo múltiplos significados, que ele tenta relacionar em um referencial constituído por três dimensões comumente usadas para descrever sistemas complexos: funcional; estrutural e comportamental.

As ações de uma pessoa são permeadas pela forma como ela concebe sua participação em certo ambiente, em uma determinada comunidade, ou mesmo, mais amplamente, como ela compreende sua atuação em sociedade. Essa concepção constitui uma coreografia do seu fazer. Isto significa que o conhecimento expresso nas ações de um sujeito é desenvolvido e orientado funcionalmente. Uma visão social de funcionalidade destaca o propósito, as intenções decorrentes do papel a que um sujeito se atribui em sociedade. Portanto, o conhecimento é inseparável da identidade do sujeito, é historicamente e funcionalmente situado como conhecimento de uma pessoa que atua na sociedade de certa forma, guiada por determinados propósitos.

Essa atuação em sociedade não é simplesmente fazer algo. Uma coreografia complexa está a permeá-la, expressando um senso de lugar, de identidade social, a regular o comportamento. A concepção do que um sujeito está fazendo, e, portanto, do contexto de suas ações, é sempre social, ainda que ele esteja só. O conhecimento de um especialista é situado, pois reflete uma compreensão sobre as atividades da comunidade de que faz parte, sobre os valores que orientam as condutas compreendidas como desejáveis, corretas, dignas de reconhecimento pelos pares. É especialmente situado porque reflete como o sujeito interpreta tudo isso e como se posiciona diante de um determinado grupo social. Essa conceitualização do contexto, que expressa o aspecto funcional da cognição situada, é comparada por Clancey como a água na qual o peixe nada: é tácita, preenche todo o ambiente e é necessária. 
Ao discutir o aspecto estrutural do termo situado, Clancey toma como exemplo a percepção e interpretação de desenhos. Observadores percebem desenhos bidimensionais como tridimensionais porque concebem tais desenhos como se referindo a coisas do mundo. Se o desenho é o de pessoas em um jardim, é bastante difícil olhar para o desenho e ver nele apenas um conjunto abstrato de linhas sem nenhuma referência a pessoas e árvores. A integração dos traços percebidos é imediata e expressa um acoplamento dinâmico, entre percepção e atribuição de significado. Nessa perspectiva a observação é interativa, pois o observador elabora um significado que não está no desenho bidimensional, mas na interação que estabelece com os traços da tela. O observador constrói uma estrutura que expressa um significado. Essa não é dada previamente por qualquer tipo de fonte. Ao fazê-lo coordena percepção, concepção e ação, em um processo de realimentação contínua.

O aspecto comportamental denota a reflexividade do comportamento, que é continuamente ajustado. A percepção continuada que um sujeito tem do que faz, de como o seu agir modifica o ambiente a sua volta ou de como o ambiente se configura a partir desse agir, definem e direcionam, permanentemente, suas ações.

Tal compreensão do caráter situado da cognição subsidiou nossas ações de descrição e compreensão da dinâmica de interações da sala de aula.

Do ponto de vista metodológico, admitir o caráter situado da cognição, nos moldes aqui apresentados, deu significado à abordagem descritiva que queríamos fazer da sala de aula e que se fundamentava na etnometodologia. De acordo com essa perspectiva de pesquisa, a realidade da sala de aula se faz pelo trabalho interpretativo de alunos e professor. A atividade permanente de interpretação do que se faz e do que ocorre produz e organiza as muitas circunstâncias do cotidiano escolar. HOLSTEIN and GUBRIUM (1994) discutem um modelo de interpretação dos fatos sociais, baseado em indivíduos com competência para interagir, que constróem, permanentemente, a ordem social através de uma ação interpretativa, contextualizada, contingente e contínua. Essa aproximação, chamada etnometodologia, como indica o nome, focaliza os etnométodos, isto é, os procedimentos práticos cotidianos para criar, sustentar e gerenciar a realidade objetiva (COULON, 1995).

A natureza situada da cognição conecta-se com a perspectiva etnometodológica na medida em que destaca o caráter funcional e comportamental 
dos processos cognitivos. Identificar e descrever os etnométodos de uma sala de aula é, justamente, desvelar a coreografia do fazer nesse contexto. Essa coreografia se compõe: dos papéis que professor e alunos atribuem a si; de seu senso de lugar e de identidade; da compreensão do que se faz e do que se espera de cada um naquela comunidade de prática; dos valores atribuídos a diferentes condutas e o reconhecimento, muitas vezes tácito, das condutas desejáveis.

Se o foco de uma investigação está nas características da prática social que ocorre em uma sala de aula, isso implica explorar o caráter comportamental da cognição, isto é, destacar como as diferentes fontes, materiais e humanas, que compõem esse ambiente, se interrelacionam: como a resposta de um artefato, de um experimento, de uma simulação no computador, modifica as interpretações dos alunos; como as possibilidades de ação sobre imagens estáticas em um livro didático, sobre imagens em movimento na tela de um computador ou sobre montagens experimentais interferem nas interpretações dos alunos; de que maneira a própria fala modifica a compreensão de quem fala; de que modo a fala do outro compõe e modifica a compreensão de ambos os interlocutores; finalmente, como comparecem, nessa perspectiva, as intervenções do professor. Em nossa investigação, essa abordagem descritiva se fez a partir da produção de narrativas com base nos registros em áudio e vídeo. Tais narrativas se constituíram em dados de segunda ordem a partir dos quais produzimos evidências e análise (MOREIRA, 2003).

Do ponto de vista dos possíveis objetos a serem investigados na sala de aula, a natureza situada da cognição recolocou para nós a importância da percepção nos processos cognitivos, que se tornou um foco importante de investigação.

\section{3 - Percepção}

Gibson (1979) afirma que é necessário prestar atenção no mundo antes de colocá-lo em palavras. Para dizer o mundo é preciso, antes, vê-lo ou percebê-lo. Perceber precede predicar. A percepção compõe coordenações elementares, a partir das quais elaboramos inferências, representações, predicados. Perceber já é, em si, um ato.

Dialogando com DEWEY (1896/1981), reforçamos essa compreensão da percepção como um ato, não apenas como uma captura de estímulos que dispara 
uma resposta. A percepção é uma atividade coordenada que não se inicia com o estímulo sensorial. No caso da percepção visual, começa com o movimento do corpo, da cabeça e dos músculos do olho determinando a qualidade do que é percebido. A percepção, como atividade coordenada, inicia-se com o ato de ver. Trata-se de dirigir o olhar e não, meramente, captar uma sensação de luz.

Percepção e ação se constituem mutuamente. Não existem de forma independente. Compõem uma coordenação e suas significâncias respectivas emergem do papel que desempenham na manutenção e na reconstituição da coordenação. Percepção e ação constituem uma coordenação que se estabelece dentro de um ato consciente do organismo movido por um determinado objetivo. Uma visão integrada que tira a percepção da periferia da ação do organismo decorre dessa perspectiva funcional: diferentes faculdades integradas na consecução de um objetivo. A percepção resultante de um estímulo é sempre algo construído em correlação a uma resposta do organismo (CLANCEY, 1997).

A percepção realiza-se na produção do que nomeamos como categorias perceptuais. Uma categoria perceptual é uma coordenação conceitual elementar. É um tipo de informação e, como tal, não deve ser tratada como uma substância física. Uma categoria perceptual é algo dinâmico, uma relação dentro de e entre processos cognitivos. Com base em Bateson, afirmamos que a produção de uma informação, e, em nosso entendimento, de uma categoria perceptual, envolve operações que não podem ser localizadas porque não têm dimensões. A produção de uma categoria perceptual envolve estabelecimento de contrastes, de correspondências, de freqüência, de busca de simetria, congruência e conformidade. Por exemplo, para se visualizar o desenho, em preto e branco, de uma xícara contendo café e identificá-lo como tal, é preciso fazer-se um contraste entre o papel branco, traços que demarcam a xícara e uma mancha negra que representa o café. Essa operação não está no desenho, nem no espaço entre o observador e o desenho, tampouco está na mente de quem observa. Trata-se de algo construído e que não tem dimensões, sequer pode ser localizado. Isto é uma categoria perceptual, que é diferente da representação externa que a gerou. Esta, sim, tem dimensões e pode ser localizada.

A percepção expressa um processo de construção que integra o indivíduo às diferentes fontes do meio. Chamamos essa construção inicial de categoria perceptual, base para os processos de inferência, representação e elaborações 
conceituais de ordem mais alta. É possível detalhar o processo de produção de categorias perceptuais, que poderia ser chamado simplesmente de percepção? Fazemos esse detalhamento a partir de um diálogo com Maturana.

\section{4 - Acoplamento estrutural e percepção como ato generativo}

Clancey argumenta a favor de uma visão de acoplamento como mecanismo elementar de produção de categorias. Tal mecanismo se traduz em um acoplamento estrutural, que incorpora as estruturas cognitivas do sujeito, suas crenças, valores, seus interesses, mas está para além dele, congregando também diferentes fontes presentes no ambiente material, social e cultural, selecionadas pelo sujeito no processo de cognição.

Nesse mecanismo de acoplamento, a história de transações de um aprendiz com seu ambiente, nas suas múltiplas dimensões - material, social e cultural - é um fator determinante das interações que pode estabelecer. Essa história interfere diretamente na forma como objetos e eventos do meio são percebidos e transformados em oportunidades para ação. Essa história de interações se expressa nos valores, crenças e interesses que mobilizam a ação do aprendiz. Manifestam-se nos chamados conhecimentos prévios que direcionam interpretações e ações correntes. Em sua atuação sobre o meio, o aprendiz modifica o percebido que, por sua vez, interferirá nas ações subseqüentes. No sistema aprendiz-ambiente material, social e cultural, o aprendiz age sobre e percebe o ambiente à sua volta. $\mathrm{O}$ ambiente sofre a ação e co-determina a percepção.

MATURANA (1983), citado por CLANCEY (1997), considera o sistema cognitivo humano como um sistema determinado em estrutura. Em um sistema determinado em estrutura, os componentes operam dentro de um espaço de configurações do todo. Qualquer configuração compromete todos os componentes.

As estruturas internas constituem e sustentam o seu próprio espaço de configurações. Em outros escritos, Maturana, juntamente com Varela, trabalha com algumas situações envolvendo percepção visual para esclarecer as características de um sistema determinado em estrutura. Esses pesquisadores argumentam que a cor dos objetos não é determinada pelas características da luz que recebemos deles. "(...) a experiência da cor corresponde a uma configuração específica de estados de atividade do sistema nervoso determinados por sua estrutura" 
(MATURANA e VARELA, 1995: 65). Tais estados poderiam ser produzidos por uma gama variada de estímulos. A sensação da cor verde não é determinada necessariamente pela chegada de uma onda eletromagnética com freqüência em torno de $5,6 \times 10^{14} \mathrm{~Hz}$. A sensação da cor verde refere-se a certo estado de atividade neural que pode ser disparado pela recepção de luz de freqüência correspondente ao verde como também pela conjugação de uma sensação anterior com outra no presente. Um disco negro inscrito em um quadrado verde (sensação anterior) resulta em um disco verde sobre um quadrado rosa quando fixamos o olhar sobre uma parede branca (sensação no presente).

Segundo Maturana e Varela, a cor que percebemos não é uma qualidade dos objetos e da luz irradiada ou refletida por eles. É possível relacionar cores a estados de atividade neural, mas não é possível relacionar uma cor percebida a certa freqüência da luz recebida, isto é, a certo estímulo específico. Isso é válido para todas as dimensões da experiência visual: movimento, textura, forma etc. e também para qualquer outra modalidade perceptiva.

Esses pesquisadores salientam o que nos parece ser uma tese fundamental:

“(...) nossa experiência está indissociavelmente amarrada à nossa estrutura (...) ao examinarmos mais de perto como chegamos a conhecer esse mundo, sempre descobriremos que não podemos separar nossa história de ações - biológicas e sociais - de como ele nos parecem ser" (MATURANA e VARELA, 1995: 66).

Interpretamos a produção de categorias perceptuais como o resultado de um acoplamento estrutural, um acoplamento entre a estrutura cognitiva do aprendiz e a estrutura do meio. Esse acoplamento possibilita uma nova unidade de análise que está para além do sujeito, congregando componentes materiais, culturais e sociais do ambiente.

Compreendemos 0 acoplamento estrutural como traduzindo 0 caráter distribuído da cognição (SALOMON, 1997). Um ambiente de aprendizagem, no contexto da educação escolar, por exemplo, pressupõe a existência de uma estrutura que congrega diferentes fontes: artefatos cognitivos diversos como livros, computador, materiais experimentais, lápis e papel. Essas fontes são dispostas de uma forma mais ou menos estruturada juntamente com orientações para o 
desenvolvimento de atividades. Professores e alunos podem ser considerados como fontes humanas de interação nesse meio.

O aprendiz comparece nesse ambiente com sua estrutura cognitiva, que deve ser interpretada em sentido amplo, isto é como uma estrutura encarnada em que aprender significa uma ação de corpo inteiro integrando sistema nervoso, cérebro, órgãos sensoriais e motores, conhecimentos prévios, crenças, valores, interesses, sentimentos. Podemos interpretar a ação do aprendiz como uma interação entre uma estrutura complexa, o corpo que conhece, e um meio pretensamente estruturado com certos objetivos.

O caráter distribuído da cognição decorre de um acoplamento entre estruturas, com certo grau de estabilidade e com uma interferência recíproca disparada continuamente por ambas as estruturas. A ação do aprendiz sobre esse ambiente de aprendizagem modifica esse ambiente, ininterruptamente. As possíveis mudanças são determinadas pela estrutura desse ambiente. De forma simultânea, isto é, dentro de um processo de realimentação contínua, a estrutura do aprendiz modifica-se, modificações essas também determinadas pela configuração de sua estrutura cognitiva, a cada momento.

Se há o acoplamento entre estruturas, dito de outro modo, se há a distribuição da cognição, o que temos, do ponto de vista de um observador externo à interação é uma nova totalidade congregando as estruturas do aprendiz e do meio. Essa configuração é tal que nas realizações dessa nova unidade não é possível especificar a contribuição de cada estrutura componente de forma isolada ou independente da contribuição da outra e das relações que caracterizam a unidade como uma nova organização: aprendiz-agindo-no-ambiente-de-aprendizagem. Uma vez que tal acoplamento se constitua e ganhe estabilidade, ele inicia sua própria história de mudanças estruturais, podendo realizar ações cada vez mais complexas e com maior autonomia.

Nesse acoplamento estrutural, a informação perceptual existe dentro de um processo de categorização que integra percepção, concepção e ação. A informação não deve ser concebida como algo externo ao sujeito, com dimensões e localizável, como um conjunto de instruções a determinar completamente o seu comportamento. Pode-se atribuir esse objetivo a uma determinada representação externa. Mas a informação elaborada pelo sujeito, no ato de interpretar, não pode ser reduzida ao processo observável, nem pode estabelecer-se uma correspondência estrita entre 
as intenções de quem gerou a representação e o conteúdo da informação produzida mediante coordenações percepto-motoras-conceituais.

Assumir o acoplamento estrutural como mecanismo elementar de produção de categorias implica em entender a percepção como ato generativo. As ações de prestar atenção, focalizar o olhar devem ser compreendidas como aspectos de uma teoria da percepção. Prestar atenção, olhar envolve um mecanismo de 'detecção', de 'captura' de informação de interesse. Utilizando termos de BATESON (1972) a captura de estímulos na percepção envolve selecionar diferenças que fazem a diferença. A informação produzida nesse processo não é propriedade inerente aos objetos e eventos do ambiente, mas uma relação dinâmica construída por acoplamento estrutural, e se expressa em uma coordenação que integra percepção, concepção e ação. Nesse sentido perceber é construir uma coordenação conceitual elementar.

Perceber é um ato generativo e constitutivo da elaboração de conceitos. Propomos a hipótese de que se na elaboração de um conceito for possível identificar categorias perceptuais, essas, certamente, compõem um substrato, de caráter elementar. Identificá-las permitirá situar melhor o processo de aprendizagem vivido pelo aprendiz e proverá indicadores da melhor forma de intervir no ambiente escolar.

Com base em DEWEY (1981), Clancey propõe uma propriedade chave da arquitetura mental:

(...) Seqüências de atos são compostas de modo que experiências subseqüentes categorizam e, então, dão significado ao que foi experienciado antes. Categorização de detalhes perceptuais emerge então junto com a categorização contínua de 'o que eu estou fazendo agora'. O significado não é gravado com fatos armazenados sobre conceitos, mas é inerente a experiência de um detalhe perceptual dentro de uma seqüência contínua de interações (...) (CLANCEY, 1997:95-96)

Esse caráter contínuo da experiência é o elemento de ligação para tratar a cognição como um fenômeno congregando o indivíduo, mas se realizando para além dele, especialmente nos níveis elementares da percepção. Fazemos aqui a abertura para as contribuições do nosso estudo sobre fenomenologia, que orientou nossa investigação sobre práticas de interpretação em diferentes ambientes de 
aprendizagem, de modo a reconhecer o caráter contínuo da experiência vivida por alunos e professores. Essa reflexão sobre a fenomenologia levou-nos a tratar a produção de enunciados, sua delimitação e transcrição como um recorte dessa experiência vivida. Acentuou, por um lado, a perspectiva parcial de nossas descrições em relação à inteireza do vivido. Por outro, qualificou nossa compreensão sobre a percepção como uma abordagem que reconhece os dados fenomenológicos e que procura fazer inferências sobre eles. Mas o que entendemos por dados fenomenológicos?

\section{5 - Dados Fenomenológicos}

Uma abordagem da cognição com base na fenomenologia significa buscar formas de relacionar os domínios mental e material. Significa pressupor a existência de dados fenomenológicos, que expressariam um acoplamento entre o mental e o material. Focalizar os dados fenomenológicos implica em pensar a mente como algo que se projeta para o mundo cognoscível.

Maturana e Varela afirmam que "(...) não há descontinuidade entre o social e o humano e suas raízes biológicas. O fenômeno do conhecer é um todo integrado, e todos os seus aspectos estão fundados sobre a mesma base" (MATURANA e VARELA 1995: 69). Nesses pressupostos buscamos suporte para abordar a cognição de um ponto de vista da continuidade entre o mental e o material. As referências advindas de uma abordagem situada da cognição também caminham nesse sentido. A abordagem situada da cognição está mais próxima dos dados fenomenológicos, uma vez que compreende a mente como constitutiva do corpo e, nele, a mente se conecta aos elementos e sujeitos do ambiente ao seu redor. Se tomarmos como base estudos sobre cognição situada (CLANCEY, 1996, 1997; MOREIRA e BORGES, 2001, 2002; MOREIRA, 2003), acreditamos fazer uma abertura para considerar evidências em que o vivido não é inteiramente comunicável. O vivido é o fenômeno e nele o mental e o material constituem uma única totalidade.

A mente pode ser compreendida como uma dimensão do ser que se constitui a cada ação do sujeito, que se projeta para fora do sujeito, articulando de forma unitária aspectos internos e externos. Alguns desses aspectos internos não são acessíveis à consciência do próprio sujeito. Outros, mesmo sendo acessíveis, não 
podem ser completamente comunicados. Essa seria a perspectiva que incorpora os dados fenomenológicos, possibilitando superar a descontinuidade entre o mental e o material. Significa enfrentar a circularidade de refletir sobre a experiência de conhecer, como salientam Maturana e Varela. Essa reflexão sobre a experiência de conhecer pode ser iluminada se buscamos compreender 0 significado de intencionalidade e de uma ação constitutiva da consciência.

\section{1 - Intencionalidade e noemática}

Segundo ROY et al (1999), a intencionalidade expressa uma propriedade fundamental da consciência. Compreender a intencionalidade se inscreve em uma tarefa de elucidar a estrutura dos dados fenomenológicos. Salientam ainda que os elementos noéticos, que compreendemos como atos da consciência, estão no núcleo central da relação intencional, assim expressa por Dartigues:

"O princípio da intencionalidade é que a consciência é sempre 'consciência de alguma coisa', que ela é consciência estando dirigida a um objeto (sentido de 'intentio'). Por sua vez, o objeto só pode ser definido em sua relação à consciência, ele é sempre 'objeto para um sujeito'. (...)" (DARTIGUES, 1992: 181)

Ao referir-se aos atos da consciência, Dartigues apresenta a imagem de uma consciência que se projeta para fora de si própria, para o objeto, e do objeto como referente, sempre, aos atos da consciência. Para ROY et al (1999), o noema expressa a atividade constitutiva da consciência na sua relação com o mundo e, ao mesmo tempo, é a estrutura intermediária necessária mediando a relação intencional entre o mundo e um sujeito cognoscente, que é capaz de transcender a experiência vivida, recortando-a, refletindo sobre ela, comunicando-a a outros.

Compreendemos o noema como um dado fenomenológico. O noema é um construto da consciência. Expressa a idéia de que todo conhecer é produzir um mundo (MATURANA e VARELA, 1995). Significa a impossibilidade de acesso ao mundo tal qual ele é. Mas significa também a possibilidade de conhecer esse mundo de um modo pessoal. E operando sobre o noema, transcendendo-o, construindo representações, comunicando-as, submetendo-as a diferentes interlocutores, construir uma certeza compartilhada. Realizar a objetividade nesse domínio das 
trocas entre pessoas que se comunicam. Admitir a necessidade de investigar essa atividade constitutiva da consciência e focalizar o noema significa incorporar os dados fenomenológicos à pesquisa cognitiva, significa tentar superar a descontinuidade entre o mental e o material. Seria a contribuição da fenomenologia para a compreensão da cognição.

ROY et al (1999) salientam que a investigação dessa ação constitutiva da consciência é suplementada por fenômenos mais específicos organizados em diferentes linhas como: percepção transcendente, consciência do tempo, consciência do corpo vivido e percepção do outro. Façamos essa discussão para a consciência do tempo.

\section{2 - Consciência do tempo}

Segundo Roy e colaboradores (1999), a análise fenomenológica do tempo é uma ilustração clara do projeto de Husserl. É um exemplo concreto do 'colocar entre parêntese' metodológico, da suspensão de qualquer crença a respeito de um tempo objetivo. Husserl focaliza essa investigação do tempo na constituição do fenômeno de duração de um objeto, como um som estendido ou uma melodia. A constituição do fenômeno de duração não pode ser entendida com base em uma sucessão de eventos discretos. Os autores salientam a seguinte afirmação de Husserl: “(...) toda experiência vivida pura é sempre uma retenção de uma passada e uma protensão a uma futura” (ROY et al, 1999: 34).

Não existiria, para Husserl, uma coisa tal como um presente instantâneo puro na temporalidade da consciência (HUSSERL, 1986; ROY et al, 1999). Essa estrutura temporal específica é também o que torna possível a própria constituição do fluxo das experiências vividas. Para designar essa atividade constitutiva por meio de retenções e protensões (extensões de algo para diante), Husserl introduziu os conceitos de 'intencionalidades longitudinal e transversal'.

A intencionalidade longitudinal expressa a relação constitutiva e recíproca entre objetos do mundo e consciência, no contínuo fluir da experiência. Expressa a inteireza do vivido, a ação de uma consciência que se projeta para o mundo, tomado como referente. Expressa o domínio de constituição do noema. Buscando articular tal conceituação com as referências anteriormente apresentadas, afirmamos que pela intencionalidade longitudinal realiza-se a integração entre percepção, 
concepção e ação, concretiza-se o caráter situado e distribuído da cognição, acontece o acoplamento estrutural, assim compondo uma nova unidade de análise: aprendiz-agindo-no-ambiente-de-aprendizagem.

A intencionalidade transversal se realiza quando a continuidade é quebrada, por exemplo, quando algo não esperado acontece. A intencionalidade transversal se realiza quando recortamos a experiência, isolamos alguns de seus aspectos, buscando compreendê-la melhor. A intencionalidade transversal constitui objetos que transcendem a experiência vivida, por isso, ditos objetos transcendentes. Através da intencionalidade transversal familiarizamo-nos diretamente com os objetos contingentes individuais, dotados de propriedades sensíveis e inseparáveis de uma rede de relações causais com outros objetos do mesmo tipo.

O principal aspecto desses objetos é que eles são apreendidos como entidades espaço-temporais. Para que o objeto seja apreendido é essencial que seja localizado no espaço e no tempo. Esse atributo de espacialidade tem, segundo ROY et al (1999), uma implicação fundamental: não é possível capturar, ao mesmo tempo, todas as determinações do objeto percebido. Trata-se de um processo fragmentado através do qual o sujeito familiariza-se sucessivamente com as diferentes 'faces' de um objeto, uma após outra. Não é possível, portanto, apreender a totalidade de determinações do objeto a partir de um ato único de percepção (ROTH, 2002). A apreensão do objeto faz-se em uma seqüência de perspectivas. Qual é a conseqüência dessa apreensão sempre incompleta?

A significação do objeto físico é sempre algo mais do que o efetivamente percebido, pois o percebido é em si uma perspectiva momentânea do objeto. Para conferir-lhe uma totalidade de coisa percebida, o sujeito agrega algo ao perfil apreendido e, nesse sentido, transcende o objeto. Esta característica da intencionalidade transversal se articula com o caráter estrutural da cognição situada. A cognição se expressa na elaboração de uma estrutura que não está no objeto e nem no sujeito, mas em uma relação dinâmica entre esses dois pólos.

A diferenciação entre o tempo objetivo e o tempo enquanto experiência vivida pode contribuir para uma descrição de certas situações de um modo novo (MOREIRA e BORGES, 2004). O tempo objetivo é o tempo delimitado e contado em intervalos regulares, expressando uma intencionalidade transversal. O tempo, enquanto experiência, vivida não admite a fragmentação. É o fluir contínuo, no domínio da intencionalidade longitudinal. 
Trabalhamos com a hipótese de que em nossa prática docente atuamos, sobretudo, no domínio da explicação, do registro. Regidos por uma intencionalidade transversal, direcionamos o processo de compreensão para patamares cada vez mais elaborados e abstratos. Poucas vezes, se é que o fazemos, colocamos 'entre parênteses' esse domínio da explicação e invertemos o sentido da interação para a experiência de observação vivida pelos alunos. Esta se realiza no domínio de uma intencionalidade longitudinal, não completamente acessível, não completamente comunicável por eles, mas matéria fundamental na produção de conhecimentos comunicáveis.

O complemento dessa hipótese é o de que focar a percepção é um caminho promissor para efetivar essa inversão. Em vez de passar rapidamente ao domínio do explicado, ater-se ao domínio do percebido. Navegar do objeto, transcendido e comunicado, para a experiência vivida da qual emergiu. O que percebeu? $\mathrm{O}$ que sentiu o nosso aluno? Empregar mais tempo nessas perguntas, indagar-se sobre os particulares do meio que o aluno integrou, sobre as diferenças que fizeram diferença para ele. Esses elementos são fundamentais para as compreensões que o nosso aluno elabora. São essenciais para os modelos que constrói e como os representa, para os enunciados que produz na explicação de um problema (MOREIRA e BORGES, 2002).

\section{6 - Direções para o olhar}

A figura 01 expressa as direções cuja articulação resulta em um referencial para a cognição em sala de aula. A abordagem situada da cognição levou-nos a recolocar a discussão sobre o papel da percepção nos processos cognitivos, especificamente nas atividades de interpretação dos alunos. Na percepção, a consciência do sujeito projeta-se para fora, se acopla com as diferentes fontes do meio, materiais e humanas, formando uma unidade que, no domínio de uma experiência primária, integra o sujeito e a vizinhança com a qual interage. Realizase, portanto, o caráter distribuído da cognição. O conhecimento produzido nesse acoplamento não é completamente explicitável pelo sujeito. Comparecem nele elementos tácitos, que expressam a história de transações do sujeito e compõem suas crenças, valores, formas de ver e verdadeiras intenções. Esses elementos tácitos e essa história de transações determinam as diferenças do meio que fazem 


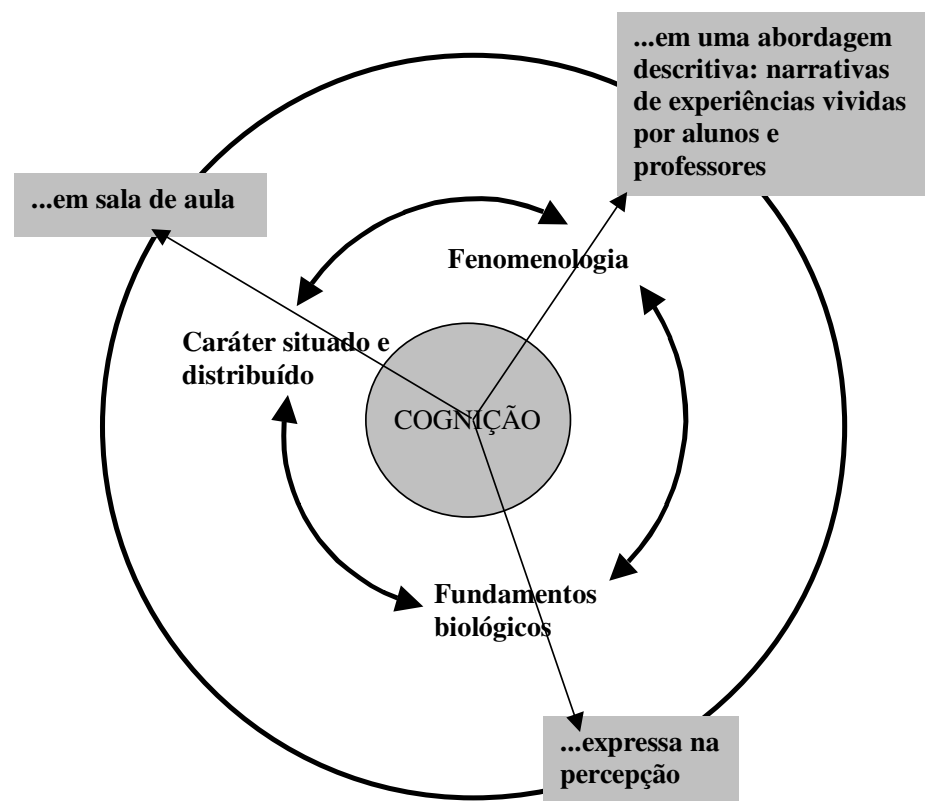

Figura 01 - Perspectivas sobre a cognição

diferença para o sujeito. Essa experiência vivida não é completamente comunicável por quem a vivencia e nem completamente acessível para quem a observa.

Propomos o foco no modo de aparecer do fenômeno para o sujeito, que dele participa e é protagonista de sua constituição. Em nossas investigações, o tipo de dado trabalhado e a forma de analisá-lo situaram-se no domínio de um observador que focaliza as ações de alunos interpretando imagens e estruturas dinâmicas. Um observador, que com base em registros de áudio e vídeo, elabora narrativas sobre as situações vividas por alunos e professor na sala de aula. A narrativa é o instrumento de produção de significado que busca abarcar a inteireza do vivido. Do ponto de vista do método, uma vez produzida, é trabalhada como um dado de segunda ordem, que objetiva a unidade entre fala e ação dos sujeitos investigados. Permite a reflexão sobre as ações concatenadas por alunos e professor e a partir daí uma abordagem que descreva a sala de aula e seus etnométodos.

Discutimos a percepção a partir dos aspectos que lhe são imanentes. Temos como pressuposto que a percepção compõe uma experiência primária, imanentemente. Elegemos como referência a visão de um sistema cognitivo encarnado que, no domínio de uma experiência primária, fundada na percepção, se acopla inteiro, participando de uma cognição distribuída. Quais as características de uma experiência primária de interpretação e como ela se integra com elaborações conceituais de ordem mais alta? Ao realizar essas elaborações de ordem mais alta, 
o sujeito se distingue do meio e comunica as suas vivências, os seus conhecimentos, as coordenações que ele é capaz de estabelecer, através de representações.

Propomos a noção de categoria perceptual como um construto a ser utilizado na descrição da experiência primária de, por exemplo, perceber objetos em movimento. O que é percebido? Como o percebido é visto pelo aprendiz? Ao respondermos a questões desse tipo, buscando identificar categorias perceptuais, acreditamos estar inferindo o substrato sobre o qual o aprendiz opera para comunicar sua interpretação.

Interpretar é um processo que inicia sua realização no ato de ver, nas diferenças selecionadas, em uma reciprocidade permanente entre o aprendiz, com sua história e intenções, e o meio, com suas características e fontes diversas. Em nossa investigação, esse meio foi a sala de aula, considerada como uma comunidade de prática, na qual se realiza uma prática social com características próprias. Aspectos dessa prática foram objetos de descrição, com base em registros em áudio e em vídeo.

Concluímos salientando que o ponto de partida para discutir o papel da percepção foi a compreensão do caráter situado da cognição, pelas lentes de Clancey. A abordagem situada da cognição, na dimensão funcional e comportamental, conecta-se com o foco nos etnométodos da comunidade investigada. Essas duas vertentes articuladas, etnometodologia e cognição situada, se apresentaram como ramificações de um tronco comum, que tinha raízes na fenomenologia. Isto levou-nos ao diálogo que alguns estudiosos da ciência cognitiva estabeleceram com as elaborações de Husserl. Remeteu-nos aos fundamentos biológicos do conhecer, propostos por Maturana e Varela. Conduziu-nos também a leituras de trabalhos de Husserl.

As referências apresentadas nesse artigo, que têm como base a visão da cognição como fenômeno, fundamentam-se nesse diálogo da cognição situada com a fenomenologia. Buscamos apresentá-las de forma articulada como um possível referencial para investigar a sala de aula, dentro de uma perspectiva ecológica, o mais próximo possível dessa comunidade de prática, no seu fazer, no seu realizar. 


\section{7 - Referências Bibliográficas}

BARTLETT, F. C. Remembering: A study in experimental and social psychology (reprinted). Cambridge: Cambridge University Press, [1932] 1977.

BATESON, G. Steps to an ecology of mind. New York: Ballantine Books. 1972.

CLANCEY, W. J. Conceptual coordination: abstraction without description. International Journal of Educationa Research, 27(1), p.5-19, 1996.

CLANCEY, W. J. Situated Cognition; On human knowledge and computer representation. New York: Cambridge University Press, 1997. 406 p.

COULON, A. Etonometodologia e Educação. In: FORQUIN, J.C. (Org.); Socilogia da Educação. Dez anos de pesquisa. Trad. Guilherme João de Freitas Teixeira. Petrópolis: Vozes, 1995. cap.6, p.300-349.

DARTIGUES, André. O que é a fenomenologia. Tradução de Maria José J. G. de Almeida. $3^{\underline{a}}$ ed. São Paulo: Editora Moraes, 1992, 174p.

DEWEY, J. Experiência e Natureza. In: Pensadores. São Paulo: Abril Cultural, 1974a.

DEWEY, J. Experiência e Natureza. In: Pensadores. São Paulo: Abril Cultural, 1974b.

DEWEY, J. The reflex arc concept in psychology. Psychological Review. 3: 357-370, [1896] 1981.

GIBSON, J. J. The ecological approach to visual perception. Boston: Houghton Mifflin, 1979. 
HOLSTEIN, J.A. and GUBRIUM, J.F. Fenomenologia, Etnometodologia e Prática Interpretativa . In: DENZIN, N. K. and LINCOLN, Y. S. (ed.) Handbook of Qualitative Research. London: Sage Publications, 1994. p. 262 a 272.

HUSSERL, E. A idéia da fenomenologia. Tradução de Artur Morão. Lisboa: Edições 70, 1986. 133p. (Coleção Textos Filosóficos, 8)

JAMES, W. Pragmatismo. In: Pensadores. São Paulo: Abril Cultural, 1974.

MATURANA, H. R. e VARELA, F. G. A árvore do conhecimento. As bases biológicas do entendimento humano. Campinas: Editorial Psy II, 1995. 281p. (Traduzido da edição, em alemão, por Jonas Pereira dos Santos.)

MATURANA, H.R. What is it to see? Que és ver? Archivos de Biologia y Medicina Experimentales. 16, 255-269, 1983.

MOREIRA, A. F. e BORGES, O. Percepção e elaboração de conceitos. In: ENCONTRO DE PESQUISA EM ENSINO DE FÍSICA, 8, 2002, Águas de Lindóia, SP. Atas [CD-ROM]. Organizadas por Deise M. Vianna, Luiz O. Q. Peduzzi, Oto N. Borges, Roberto Nardi. São Paulo: SBF, 2002.

MOREIRA, A. F. e BORGES, O. Práticas de interpretação mediadas por experimentos e simulações. In: ENCONTRO DE PESQUISA EM EDUCAÇÃO EM CIÊNCIAS, 3, 2001, Atibaia, SP. Atas [CD-ROM]. Organizadas por Marco Antônio Moreira, lleana Maria Greca e Sayonara Cabral da Costa. Porto Alegre : s.n., 2001.

MOREIRA, A. F. e BORGES, O. Tempo vivido e tempo medido. Trabalho aceito para comunicação oral In: ENCONTRO DE PESQUISA EM ENSINO DE FÍSICA, 9, 2004, Joatuba, MG.

MOREIRA, A. F. Práticas de interpretação em ambientes de aprendizagem de Física. Belo Horizonte, UFMG, 2003, Tese de Doutorado, 180p 
ROTH, W.M. From stimulus to science: the changing nature of visual perception. In AMERICAN EDUCATIONAL RESEARCH ASSOCIATION Annual Meeting. New Orleans, April 1-5, 2002.

ROY, J-M; PETITO, J.; PACHOUD, B. and VARELA, F.J. Beyonde the gap: na introduction to naturalizing phenomenology. In: Naturalizing Phenomenology. Issues in contermporary phenomenology and cognitive science. Standford: Standford University Press, 1999. (cap.1, p.1-80)

SALOMON, G. (Ed.) Distributed Cognitions. Psychological and educational considerations. Cambridge University Press: 1997. cap.4. p.111-138.

Data de recebimento:30/05/2005

Data de aprovação: 10/04/2006 